\title{
DIFFERENT PROCESSES CONTRIBUTING TO THE DEVELOPMENT OF PREFERRED ORIENTED PLATINUM SURFACES BY FAST PERIODIC POTENTIAL PERTURBATION TECHNIQUES
}

\author{
C.L. PERDRIEL, W.E TRIACA and A.J. ARVIA \\ Instituto de Investigactones Fisicoquimicas Teóncas y Aplicadas - INIFTA, Casilla de Correo 16, Sucursal 4. \\ 1900 La Plata (Argentina)
}

(Received 7th October 1985; in revised form 18th January 1986)

\begin{abstract}
The development of preferred oriented (po) platınum surfaces, either [(100)poPt] or [(111)poPt], in acid solutions results from the contributions of electroadsorption/electrodesorption processes and electrodissolution/electrodeposition of platinum. In the case of [(100)poPt], the overall reaction implies no appreciable roughening, whereas for $[(111) \mathrm{poPt}]$ the voltammetric charge increases slightly after the preferred orientation treatment. Runs were made with perıdıc potential scans, either triangular or rectangular, under conditions corresponding to the optimal conditions for development of the [(100)poPt] and [(111)poPt] surfaces. The amount of net soluble platinum as determined by chemical analysis increases linearly with the duration of the periodic potential perturbation applied to the platinum polycrystalline electrode. The net amount of dissolved platinum produced at perturbation frequencies required for the developinent of the preferred orientation is nearly two orders of magnitudes smaller than that found under conventional triangular potential voltammetry. The results offer the possibility of interpretıng the electrochemical faceting of platinum electrodes in acid electrolytes.
\end{abstract}

\section{INTRODUCTION}

In the last decade numerous publications have dealt with voltammetric techniques used extensively to study electroadsorption and electrodesorption of different species on noble metal electrodes but in most of these works relatively little attention has been concentrated on changes in the electrode surface structure caused by both the different electroadsorption/electrodesorption processes taking place during the potential scanning and the proper electrodissolution of the base metal.

Early radiochemical data [1,2] showed that the steady-state rate of platinum dissolution is approximately equal in various inorganic acids. The approximate current density value at $1.0 \mathrm{~V}$ was estimated as $10^{-9} \mathrm{~A} / \mathrm{cm}^{2}$. The rate of the reaction decreased with time at constant potential, presumably because of the adsorption of oxygen. A much greater rate of electrodissolution was found under periodic potential perturbation techniques covering the potential range where there was no equilibrium coverage of adsorbed oxygen $[3,4]$. 
The electrodissolution of platinum in perchloric and sulphuric acid solutions was also studied by applying the RRDE technique [4]. The potential of the platinum disk was cycled between 0.45 and $1.45 \mathrm{~V}$, and gold or platinum rings, held at various potentials, were used to monitor any formation of soluble species. The quantity of metal in solution amounted to $4.5 \times 10^{-3} \mu \mathrm{g} / \mathrm{cm}^{2}$ per cycle.

The potential cycling of a platinum electrode between 0.41 and $1.46 \mathrm{~V}$ in $1 \mathrm{M}$ sulphuric acid dissolves $30 \mu \mathrm{C} / \mathrm{cm}^{2}$ on each $40 \mathrm{mV} / \mathrm{s}$ per cycle [3]. This amounts to an average electrodissolution current of $4 \times 10^{-7} \mathrm{~A} / \mathrm{cm}^{2}$ that is nearly two orders of magnitude greater than in the steady state, despite the fact that the electrode is at potentials below the corrosion region for most of the cycle. In this case, the quantity of metal in solution is $5.5 \times 10^{-3} \mu \mathrm{g} \mathrm{cm}^{-2} \mathrm{cycle}^{-1}$, a figure which compares favourably with the one reported above [4]. The anodic to cathodic charge difference $\left(Q_{\mathrm{a}}-Q_{\mathrm{c}}\right)$ on repetitive triangular potential cycling for platinum electrodes can be explained by metal electrodissolution. The charge of the latter amounts to $1 \%$ of the total anodic charge passed in the oxygen adsorption region.

There is convincing evidence that there are changes in the surface topography brought about by anodic-cathodic treatments of platinum electrodes. Generally there is roughening of the surface of platinum wires and foils, but smoothing has also been reported for the application of some potential programmes. even for nominally smooth platinum electrodes [5.6]. Roughening has been explained in terms of the redistribution of surface metal atoms brought about by forming and breaking $\mathrm{Pt}-\mathrm{O}$ bonds. It takes place only when more than one oxygen atom is associated with each surface platinum atom on the anodic step [6]. Ellipsometric data [7] suggest that the second adsorbed oxygen resides below the uppermost layer of platinum atoms, which would aid reconstruction of the surface on desorption. More recently, electrodissolution, roughening and sintering effects were found for palladium in acid by using RRDE [8] and thin-layer techniques [9] at relatively low voltammetric sweep rates. It should be noted that surface metal roughening due to adsorption has also been established in gas-phase studies [10].

Despite the data presented above, there has been no extensive study on the influence of the characteristics of the potential sweep on the rate of electrodissolution of metals under a periodically changing potential. The matter appears very attractive as it may become relevant for an understanding of the mechanism associated with both roughening and preferred crystallographic orientation of noble metals in acids promoted by fast periodic potential perturbations [11-14]. The three effects. namely, sintering, roughening and preferred orientation, are observed at different frequency windows of the periodic potential perturbation [6,11]. Preferred orientation of polycrystalline platinum, particularly the development of the (100) preferred oriented surface, implies practically no roughening [11-14].

This paper attempts to evaluate the net amount of soluble platinum produced in acid from a polycrystalline platinum electrode perturbed by either a fast triangular or square-wave potential signal under the optimal conditions, reported recently [14], required to transform the polycrystalline platinum electrode surface into either a (100) preferred oriented platinum [(100)poPt] or a (111) preferred oriented platinum 
[(111)poPt] electrode surface. In addition, these results offer the possibility of interpreting the initial stage of the preferred orientation effect and its propagation into the "bulk" of the metal, to such an extent that surface faceting patterns can be observed by SEM at a relatively low magnification [13].

\section{EXPERIMENTAL}

The electrochemical cell consisted of two glass compartments. One of them was a cylindrical compartment of ca. $10 \mathrm{~cm}^{3}$ to house the working electrode and the counter-electrode. The second compartment was used to place the reference electrode. The working electrode was made of a polycrystalline platinum wire (Johnson Matthey, Specpure grade) of apparent area ranging from 0.16 to $0.33 \mathrm{~cm}^{2}$. The electrode tip was sealed in a small glass bead to assure a good current distribution. The working electrode was electropolished as indicated elsewhere [12] and stored in Milli Q water until use. A large-area graphite (National, spectroscopically pure) counter-electrode was placed parallel to the working electrode to minimize ohmic drop effect. A reversible hydrogen electrode (RHE) in the same electrolyte solution ( $1 \mathrm{M} \mathrm{H}_{2} \mathrm{SO}_{4}$ ) was employed as the reference. Potentials in the text are referred to the RHE scale. Runs were made at $25^{\circ} \mathrm{C}$ in $1.0 \mathrm{M} \mathrm{H}_{2} \mathrm{SO}_{4}$ prepared from $98 \%$ $\mathrm{H}_{2} \mathrm{SO}_{4}$ (Merck, p.a.) and Milli Q water.

The experimental procedure consisted of three stages: (i) application of the fast periodic potential perturbation to the polycrystalline platinum electrode immersed in $1 \mathrm{M} \mathrm{H}_{2} \mathrm{SO}_{4}$ to develop the preferred orientation and to accumulate soluble platinum species in the electrolyte solution; (ii) voltammetric characterization of the preferred oriented surface after stage (i) at $0.1 \mathrm{~V} / \mathrm{s}$ in fresh $1 \mathrm{M} \mathrm{H}_{2} \mathrm{SO}_{4}$ within the $\mathrm{H}$-adatom electroadsorption/electrodesorption potential range; (iii) chemical analysis of soluble platinum accumulated in the electrolyte solution.

The following periodic potential signals were applied to the polycrystalline platinum electrode during a certain length of time $t$ : (i) repetitive triangular potential scanning (RTPS) in the $0.05-1.45 \mathrm{~V}$ range at $3.57 \mathrm{kHz}$; (ii) RTPS in the $0.55-1.35 \mathrm{~V}$ range at $3.00 \mathrm{kHz}$; (iii) repetitive square-wave potential scanning (RSWPS) in the 0.21-1.28 V range at $4.00 \mathrm{kHz}$; (iv) RSWPS in the $0.70-1.40 \mathrm{~V}$ range at $3.00 \mathrm{kHz}$. Conditions (i) and (iii) favour the development of [(100) poPt], whereas conditions (ii) and (iv) promote [(111)poPt] [11,12,14]. For RSWPS, the duration $\tau_{1}$ and $\tau_{11}$ of the lower $\left(E_{1}\right)$ and the upper $\left(E_{11}\right)$ potential limits, respectively, were adjusted as convenient. Most of the runs correspond to symmetric periodic potential perturbations, but runs involving application of asymmetric periodic perturbations, using $\tau_{\mathrm{u}} / \tau_{1}$ ratios equal to 3.00 and 0.33 at $3.12 \mathrm{kHz}$, were also made.

The net amount of soluble platinum produced during the fast potential scanning was determined spectrophotometrically by firstly oxidizing all soluble platinum to $\mathrm{Pt}(\mathrm{IV})$ with bromine and secondly reacting it with $\mathrm{SnCl}_{2}$ solution $[15,16]$. Analytical data were obtained in triplicate for the duration of the fast periodic potential perturbation comprising between 5 and $120 \mathrm{~min}$. Evaluation of the amount of any 
possible platinum electrodeposited on the graphite counter-electrode was done by dissolving the deposit in aqua regia and following the same analytical procedure. Under the experimental conditions of the present work, this correction was less than $5 \%$, a figure which is smaller than the reproducibility of results, particularly those obtained at the lower soluble platinum concentrations.

For the sake of comparison and in order to check the analytical procedure, runs were also made to evaluate the amount of soluble platinum produced under conventional voltammetry at a low potential sweep rate, namely, $0.040 \mathrm{~V} / \mathrm{s}$, approaching the conditions already reported in the literature [3].

\section{RESULTS}

The voltammograms resulting after applying the symmetric fast periodic perturbation treatment to the polycrystalline platinum electrodes (Figs. 1 and 2) are similar to those already reported for either [(100)poPt] or [(111)poPt] in $1 M \mathrm{H}_{2} \mathrm{SO}_{4}$ at $0.1 \mathrm{~V} / \mathrm{s}$ [11-14]. Furthermore, the first negative scan corresponding to the development of [(111)poPt] shows a large cathodic current peak at $0.1-0.3 \mathrm{~V}$, probably related to the electroreduction of a surface oxide [17.18]. which distorts the $\mathrm{H}$-electroadsorption current peaks (Fig. 2). The second potential scan approaches the stabilized voltammetric response of $[(111) \mathrm{poPt}]$ in $1 \mathrm{M} \mathrm{H}_{2} \mathrm{SO}_{4}$ at $0.1 \mathrm{~V} / \mathrm{s}$.

The integral amount of soluble platinum per unit electrode area and per cycle $\left(m_{\mathrm{Pt}}\right)$ found in the electrolyte solution after applying the different periodic potential perturbations is summarized in Table 1. For a particular set of experiments, the
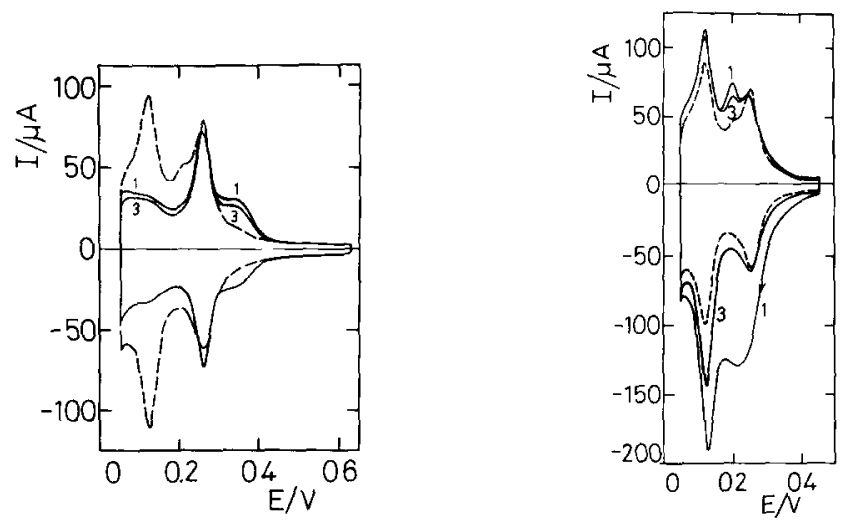

Fig. 1. Voltammograms run at $0.1 \mathrm{~V} / \mathrm{s}$ in $1 \mathrm{M} \mathrm{H}_{2} \mathrm{SO}_{4}$ at $25^{\circ} \mathrm{C}$. ) After 2 h RSWPS at $4.00 \mathrm{kHz}$ between 0.21 and $1.28 \mathrm{~V}$; (1) and (3) denote the first and third cycles, respectively. (- Electropolıshed polycrystalline electrode.

Fig. 2. Voltammograms run at $0.1 \mathrm{~V} / \mathrm{s}$ in $1 \mathrm{M} \mathrm{H}_{2} \mathrm{SO}_{4}$ at $25^{\circ} \mathrm{C}$. (—) After $30 \mathrm{~min}$ RSWPS at 3.00 $\mathrm{kHz}$ between 0.70 and $1.40 \mathrm{~V}$; (1) and (3) denote the first and third cycles. respectively. (- Electropolished polycrystalline electrode. 
TABLE 1

Amount of soluble platinum per cycle under different potentıal perturbation conditions

\begin{tabular}{llcc}
\hline $\begin{array}{l}\text { Preferred } \\
\text { orientation }\end{array}$ & $\begin{array}{l}\text { Potential } \\
\text { perturbation }\end{array}$ & Time $/ \mathrm{min}$ & $\begin{array}{c}10^{6} m_{\mathrm{Pt}} / \mathrm{g} \mathrm{cm}^{-2} \mathrm{cycle}^{-1} \\
(100)\end{array}$ \\
& RTPS & 5 & 0 \\
& 15 & $7 \pm 3$ \\
& 30 & $11 \pm 2$ \\
& 60 & $14 \pm 2$ \\
& 120 & $13 \pm 2$ \\
& RSWPS & 15 & $2.5 \pm 1.7$ \\
& 60 & $1.5 \pm 0.4$ \\
$(111)$ & 120 & $1.3 \pm 0.3$ \\
& & 30 & $11 \pm 6$ \\
& RTPS & 30 & $13 \pm 4$ \\
\hline
\end{tabular}

value of $m_{\mathrm{Pt}}$ is about $10^{-5}-10^{-6} \mu \mathrm{g} \mathrm{cm}^{-2}$ cycle $^{-1}$ and is approximately independent of $t$. Under symmetric potential perturbation conditions, either RTPS or RSWPS, which promote [(100)poPt], $m_{\mathrm{P}_{t}}$ increases linearly with $t$ (Fig. 3). The values of $m_{\mathrm{Pt}}$ resulting under different potential perturbation conditions are given in Table 2.

Voltammetric runs at $0.1 \mathrm{~V} / \mathrm{s}$ in $1 \mathrm{M} \mathrm{H}_{2} \mathrm{SO}_{4}$ were also made after applying asymmetric RSWPS, which promotes the [(100)poPt] surface. Thus, for $E_{1}=0.25 \mathrm{~V}$, $E_{\mathrm{u}}=1.25 \mathrm{~V}, f=3.12 \mathrm{kHz}$ and $t=30 \mathrm{~min}$, either for $\tau_{\mathrm{u}} / \tau_{1}=3.00$ or $\tau_{\mathrm{u}} / \tau_{1}=0.33$, the voltammograms of the resulting surfaces run at $0.1 \mathrm{~V} / \mathrm{s}$ show no appreciable changes with respect to those depicted in Fig. 1, except for a less remarkable development of the preferred orientation. However, after the RSWPS treatment for $\tau_{\mathrm{u}} / \tau_{1}=3.00, m_{\mathrm{Pt}}$ is ca. 50 times greater than that corresponding to the symmetric RSWPS (Table 3 ). Otherwise, when $\tau_{u} / \tau_{1}=0.33$, no soluble platinum was detected in solution.

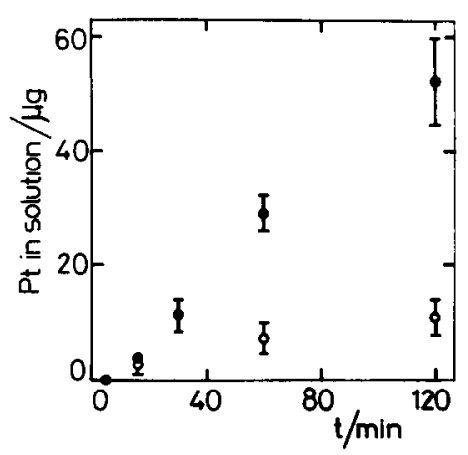

Fig. 3. Amount of dissolved platinum against the duration of the potential perturbation. (⿶) RTPS $\left(E_{1}=0.05 \mathrm{~V}, E_{\mathrm{u}}=1.45 \mathrm{~V}, f=3.57 \mathrm{kHz}\right)$. (O) RSWPS $\left(E_{1}=0.21 \mathrm{~V}, E_{\mathrm{u}}=1.28 \mathrm{~V}, f=4.00 \mathrm{kHz}\right)$. 


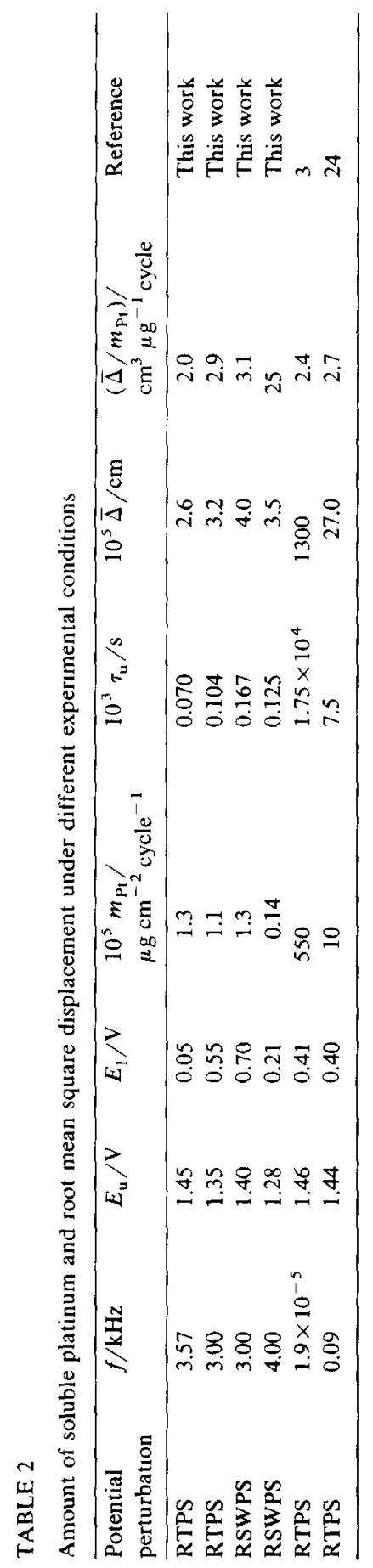




\section{TABLE 3}

Dependence of the amount of soluble platinum on the symmetry of the RSWPS ${ }^{\text {a }}$

\begin{tabular}{lcc}
\hline $\begin{array}{l}\text { Upper and lower } \\
\text { potential limits }\end{array}$ & $\tau_{\mathrm{u}} / \tau_{\mathrm{I}}$ & $m_{\mathrm{Pt}} / \mu \mathrm{g}$ \\
\hline$E_{1 \mathrm{l}}=1.25 \mathrm{~V}$ & 3.00 & $189 \pm 12$ \\
& 1.00 & $4 \pm 1$ \\
$E_{1}=0.25 \mathrm{~V}$ & 0.33 & 0 \\
$E_{\mathrm{u}}=1.40 \mathrm{~V}$ & 3.00 & $10 \pm 4$ \\
& 1.00 & $23 \pm 7$ \\
$E_{1}=0.70 \mathrm{~V}$ & 0.33 & $72 \pm 8$
\end{tabular}

d RSWPS characterıstics: $f=3.12 \mathrm{kHz} ; t=30 \mathrm{~min}$. Working electrode area $=0.33 \mathrm{~cm}^{2}$.

On the other hand, for RSWPS conditions which favour the development of [(111)poPt], the voltammetric response at $0.1 \mathrm{~V} / \mathrm{s}$ is remarkably dependent on the symmetry of the potential perturbation signal. Thus, for $E_{1}=0.7 \mathrm{~V}, E_{\mathrm{u}}=1.4 \mathrm{~V}$, $f=3.12 \mathrm{kHz}, t=30 \mathrm{~min}$ and $\tau_{\mathrm{u}} / \tau_{1}=3.00$, the voltammogram of the resulting surface (Fig. 4) shows a decrease in the development of [(111)poPt] as compared to that obtained under a comparable symmetric RSWPS (Fig. 2). In this case, no appreciable change in the roughness of the resulting surface is noticed, and $m_{\mathrm{Pt}}$ is lower than that found for a comparable symmetric RSWPS (Table 3).
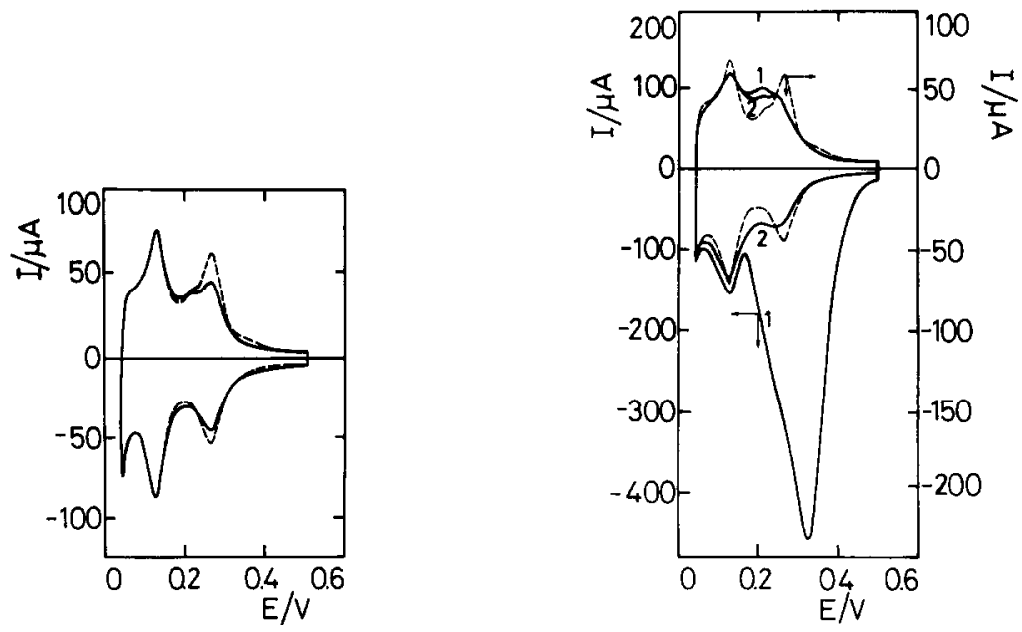

Fig. 4. Voltammograms run at $0.1 \mathrm{~V} / \mathrm{s}$ in $1 \mathrm{M} \mathrm{H}_{2} \mathrm{SO}_{4}$ at $25^{\circ} \mathrm{C}$. (—) After $30 \mathrm{~min}$ asymmetric RSWPS $\left(\tau_{\mathrm{u}} / \tau_{1}=3\right)$ at $3.12 \mathrm{kHz}$ between 0.70 and $1.40 \mathrm{~V}$. (- - Electropolished crystalline electrode.

Fig. 5. Voltammograms run at $0.1 \mathrm{~V} / \mathrm{s}$ in $1 \mathrm{M} \mathrm{H}_{2} \mathrm{SO}_{4}$ at $25^{\circ} \mathrm{C}$ ( (—) After $30 \mathrm{~min}$ asymmetric RSWPS $\left(\tau_{\mathrm{u}} / \tau_{1}=0.33\right)$ at $3.12 \mathrm{kHz}$ between 0.70 and $1.40 \mathrm{~V} ;(1)$ and (2) denote the first and second cycles, respectively ( - _ Electropolished polycrystallıne electrode. 
Likewise, for an asymmetric RSWPS with $E_{1}=0.7 \mathrm{~V}, E_{\mathrm{u}}=1.4 \mathrm{~V} . f=3.12 \mathrm{kHz}$, $t=30 \mathrm{~min}$ but $\tau_{\mathrm{u}} / \tau_{1}=0.33$, the voltammogram at $0.1 \mathrm{~V} / \mathrm{s}$ run afterwards exhibits additional distinctive features (Fig. 5). Thus, the first negative scan shows a large cathodic current peak at ca. $0.3 \mathrm{~V}$ which masks the current peak corresponding to the strongly adsorbed hydrogen [17,18], but the second potential scan approaches the stabilized voltammetric response of [(11)poPt]. In this case, an appreciable increase in the voltammetric charge as compared to that of the initial polycrystalline platinum electrode is observed, and the value of $m_{\mathrm{p}}$ is higher than that found under comparable conditions using the symmetric perturbation.

\section{DISCUSSION}

The lower and upper potential limits of the fast potential perturbations which produce either [(100)poPt] or [(111)poPt] surfaces are located at the negative and at the positive potential sides, respectively, of the equilibrium potential of the following reactions:

$$
\begin{array}{ll}
\mathrm{Pt}^{2+}+2 e^{-} \rightleftarrows \mathrm{Pt} & E_{1}^{\circ}=1.19 \mathrm{~V} \\
\mathrm{Pt}(\mathrm{OH})+\mathrm{H}^{+}+e^{-} \rightleftarrows \mathrm{Pt}+\mathrm{H}_{2} \mathrm{O} & E_{2}^{\circ}=0.85 \mathrm{~V} \\
\mathrm{Pt}(\mathrm{OH})_{2}+2 \mathrm{H}^{+}+2 e^{-} \rightleftarrows \mathrm{Pt}+2 \mathrm{H}_{2} \mathrm{O} & E_{3}^{\circ}=0.98 \mathrm{~V} \\
\mathrm{PtO}_{2}+2 \mathrm{H}^{+}+2 e^{-} \rightleftarrows \mathrm{Pt}(\mathrm{OH})_{2} & E_{4}^{\circ}=1.10 \mathrm{~V} \\
\mathrm{PtO}_{2}+4 \mathrm{H}^{+}+2 e^{-} \rightleftarrows \mathrm{Pt}^{2+}+2 \mathrm{H}_{2} \mathrm{O} & E_{5}^{\circ}=0.84 \mathrm{~V} \\
\mathrm{PtO}_{2}+4 \mathrm{H}^{+}+4 e^{-} \rightleftarrows \mathrm{Pt}+2 \mathrm{H}_{2} \mathrm{O} & E_{6}^{\circ}=1.04 \mathrm{~V}
\end{array}
$$

Despite the fact that the experiments were run under a relatively high frequency treatment far from equilibrium, the above-mentioned redox potentials were considered. as a first approximation. as operational values. The potential value of reaction (1) is shifted to less positive values when the dissolved ion is complexed, so that the metal is inherently less stable [19]. Reaction (2) is the initial reversible stage of platinum surface electrooxidation yielding adsorbed $\mathrm{OH}$ species from the upd discharge of water [20], the corresponding $E_{2}^{\circ}$ value being estimated from triangularly modulated voltammetry [21]. The potentials $E_{3}^{\circ}$ and $E_{4}^{\circ}$ are calculated from thermodynamic data of the bulk species [22,23]. The value of $E_{5}^{\circ}$ is taken from literature [19] and $E_{6}^{\circ}$ is estimated from reactions (3) and (5).

The equilibrium potential values of reactions (1)-(6) indicate that within the potential range of the fast periodic potential perturbation, redox processes associated with different oxidation states of platinum are thermodynamically possible. Furthermore, the formation of soluble platinum may imply a series of reactions similar to those usually reported in simple metallic corrosion in acid electrolytes:

$$
\begin{aligned}
& \mathrm{Pt}+\mathrm{H}_{2} \mathrm{O}=\mathrm{Pt}(\mathrm{OH})+\mathrm{H}^{+}+e^{-} \\
& \mathrm{Pt}(\mathrm{OH}) \rightarrow \mathrm{Pt}(\mathrm{OH})^{+}+e^{-} \\
& \mathrm{Pt}(\mathrm{OH})^{+}+\mathrm{H}^{+} \rightarrow \mathrm{Pt}^{2+}+\mathrm{H}_{2} \mathrm{O}
\end{aligned}
$$


Soluble platinum either as $\mathrm{Pt}(\mathrm{II})$ or $\mathrm{Pt}(\mathrm{IV})$ may result from the hydrous hydroxide and oxides involved in reactions (3) and (4)-(6) according to:

$\mathrm{Pt}(\mathrm{OH})_{2}+2 \mathrm{H}^{+} \rightarrow \mathrm{Pt}^{2+}+2 \mathrm{H}_{2} \mathrm{O}$

and

$\mathrm{PtO}_{2}+4 \mathrm{H}^{+} \rightarrow \mathrm{Pt}^{4+}+2 \mathrm{H}_{2} \mathrm{O}$

The $\mathrm{Pt}(\mathrm{II})$ and $\mathrm{Pt}(\mathrm{IV})$ species may exist as complex ions. The amount of soluble $\mathrm{Pt}(\mathrm{II})$ and $\mathrm{Pt}(\mathrm{IV})$ and their relative concentrations can be estimated from the corresponding equilibrium constants.

Reactions such as (3)-(5) have been considered to explain the roughening of platinum electrodes under repetitive potential perturbations at relatively low frequencies $[5,6,24]$. The excess charge $\left(Q_{\mathrm{a}}-Q_{\mathrm{c}}\right)$ was assigned to loss of PtO from the surface to the solution phase $[5,6]$. The importance of platinum dissolution and redeposition in the process of roughening of platinum electrodes on potential cycling has also been demonstrated [24]. In any anodic-cathodic treatment, metal dissolves anodically and a fraction of it is redeposited on the cathodic step. This process is equivalent to surface evaporation and selective condensation and is expected to produce a clean, fresh metal surface [24]. It should be noted that neither roughening nor sintering has been observed as significant effects in the frequency range where the preferred orientation effects are produced [11].

During the development of the preferred oriented platinum surfaces for symmetric perturbations, the amount of metal going into solution per cycle is remarkably less, by about $2-3$ orders of magnitude, than that reported during RTPS at $0.04 \mathrm{~V} / \mathrm{s}$ $[3,4]$. This decrease in the amount of net electrodissolution of platinum per cycle under fast symmetric potential perturbations suggests that the local electrodissolution/electrodeposition processes occur very fast. Accordingly, it is possible to estimate the root mean square displacement, $\bar{\Delta}$, of dissolved ionic platinum species from the metal surface at $E_{\mathrm{u}}$ during the time $\tau_{\mathrm{u}}$ through the equation $\bar{\Delta}=\left(2 D \tau_{\mathrm{u}}\right)^{1}=$ $=\left(2 D \tau_{1}\right)^{1 / 2}[25]$ (Table 2). For RTPS, $\tau_{\mathrm{u}}$ is taken as the time for which the applied potential exceeds $1.1 \mathrm{~V}$ and $\tau_{1}$ is taken as the time for which the applied potential is more negative than $0.4 \mathrm{~V}$. The value of $D$ was estimated as $5 \times 10^{-6} \mathrm{~cm}^{2} / \mathrm{s}$ because neither $\mathrm{Pt}(\mathrm{II})$ nor $\mathrm{Pt}(\mathrm{IV})$ soluble species nor their concentrations during cycling are known. and no experimental value of $D$ for those species was found in the literature.

From the small value of $\bar{\Delta}$ it is inferred that under RSWPS most of the platinum dissolved at $E_{\mathrm{u}}$ is impeded to diffuse out to the bulk solution and, therefore. it is redeposited during the negative half-cycle at $E_{1}$. For the same $E_{\mathrm{u}}$ and $E_{1}$ values, the $\bar{\Delta} / m_{\mathrm{Pt}}$ ratio turns out to be approximately frequency-independent.

From the influence of the mass transport rate on the electrochemical reaction. the ac modulation of the applied potential implies a decrease in the average thickness. $\delta_{\mathrm{N}}$. of the Nernst diffusion layer which is directly proportional to the square of the period of the ac signal [26]. The decrease in the value of $\delta_{N}$ favours the development of smooth metal electrodeposits. 
The dependence of $m_{\mathrm{Pt}}$ on $\tau_{\mathrm{u}} / \tau_{1}$ depends on whether the [(100)poPt] or the [(111)poPt] surface is obtained, namely on the $E_{\mathrm{u}}$ and $E_{1}$ values at the optimal frequency (Table 3 ). In the development of [(100)poPt], as the $\tau_{\mathrm{u}} / \tau_{1}$ ratio increases $m_{\mathrm{P}_{t}}$ increases. This means a larger amount of soluble platinum species goes into the solution as $\tau_{\mathrm{u}}>\tau_{1}$. presumably because the perturbation conditions in this case imply practically no hydrous oxide phase formation. Conversely, in the development of [(111)poPt], $m_{\mathrm{Pt}}$ decreases as the $\tau_{\mathrm{u}} / \tau_{1}$ ratio increases. There is a correlation between the decrease in $m_{\mathrm{Pt}}$ and the decrease in the voltammetric electroreduction charge found after the RSWPS treatments, at ca. $0.3 \mathrm{~V}$ in the first scan (Figs. 2, 4 and 5). This suggests that for $\tau_{1}>\tau_{\mathrm{u}}$ the asymmetric perturbation favours the roughening of the surface through the formation of a hydrous oxide layer.

It is already known that the presence of irreversibly adsorbed oxygen atoms (aged electroadsorbed oxygen atom) slows down the electrodissolution of the base metal. This typc of adsorbcd oxygen-containing species is unlikely to be formed in the working potential range under the fast RTPS: instead, the reactive oxygencontaining species participates in the overall process. This means that platinum electrodissolution and electrodeposition are facilitated as each potential scan covers positive and negative potentials with respect to that of the reversible $\mathrm{Pt} / \mathrm{Pt}(\mathrm{II})$ redox system.

On the basis of the present discussion it is unlikely that the mechanisms proposed for platinum roughening can be straightforwardly applied to explain the effect of preferred orientation. Thus, the first mechanism [3] postulated that platinum dissolution may proceed either by direct dissolution of the metal:

$\mathrm{Pt} \rightarrow \mathrm{Pt}^{2+}+2 e^{-}$

or via an intermediate surface oxygen species, e.g.:

$\mathrm{Pt}+\mathrm{H}_{2} \mathrm{O} \rightarrow[\mathrm{PtO}]^{*}+2 \mathrm{H}^{+}+2 e^{-}$

$[\mathrm{PtO}]^{*}+2 \mathrm{H}^{+} \rightarrow \mathrm{Pt}^{2+}+\mathrm{H}_{2} \mathrm{O}$

and the complementary electrodeposition should occur in the reverse direction. This mechanism explains why adsorbed oxygen inhibits dissolution, but it ignores the formation of the adsorbed $\mathrm{OH}$ species which plays a critical role in the initiation of the process of development of preferred orientation and of $\mathrm{H}$ adatoms in defining the type of prevailing preferred orientation $[27,28]$. The distinction between adsorbed $\mathrm{OH}$, active adsorbed $\mathrm{O}$ and aged $\mathrm{O}$ species is necessary in order to understand the initiation of the process.

Another mechanism for roughening is based on the reaction

$\mathrm{PtO}_{2}+4 \mathrm{H}^{+}+2 e^{-} \rightarrow \mathrm{Pt}^{2+}+2 \mathrm{H}_{2} \mathrm{O}$

but the corresponding argument both for roughening and preferred orientation is weakened by the fact that the oxygen layer on Pt cannot be identified with a phase oxide having the thermodynamic properties of $\mathrm{PtO}_{2}$ [4]. Nevertheless, it is likely that when conditions. such as those involving a relatively high positive upper potential 
limit in the fast periodic potential perturbation, are chosen so as to enhance the (111) preferred orientation [17]. reaction (11) may also become increasingly important in the development of preferred orientation.

The present results and those reported previously indicate that the initiation and propagation of faceting of polycrystalline surface comprise the electroadsorption/electrodesorption of $\mathrm{OH}$ and $\mathrm{O}$ species, the electrodissolution/electrocrystallization of platinum, the electroadsorption/electrodesorption of $\mathrm{H}$ adatoms and, at high positive upper potential limits, the electroformation of a hydrous oxide species $\left(\mathrm{PtO}_{2}\right.$ ?) and its partial or complete electroreduction at the lower potential limit.

The mechanism of the electrochemical faceting can be summarized as follows. During the positive half-cycle the first electrooxidation step comprises electroadsorption reactions at active sites of the platinum surface, probably at grain boundaries and mechanically produced defects, yielding $\mathrm{OH}$ adsorbed species, and simultaneously shifting the platinum atoms from their initial positions at the lattice. The following electrooxidation reaction may produce non-aged adsorbed $\mathrm{O}$ atoms on the same sites. The propagation stage implies the formation of soluble platinum species through ionic equilibria involving different species such as $\mathrm{Pt}(\mathrm{OH})_{d \mathrm{~d}}$ and $\mathrm{Pt}(\mathrm{OH})^{+}$and leaving fresh sites for the continuation of the electroadsorption reaction.

During the negative half-cycle the reverse reactions are accompanied by the reaccommodation of platinum atoms in the metal lattice. The presence or absence of $\mathrm{H}$-adatom electroformation during the negative stage presumably defines the type of faceting achieved by the electrochemical fast periodic perturbation treatments.

In this context one would expect that the difference in the potential of zero charge $\left(E_{g=0}\right)$ of the different crystallographic planes of the polycrystalline metal should play a decisive role in defining the relative contribution of each process involved in the electrochemical faceting, as is discussed in a forthcoming publication [29]. Unfortunately, in this respect there are no data available to verify the influence of $E_{\sigma=0}$ on the preferred orientation of polycrystalline platinum by fast periodic potential perturbations.

\section{ACKNOWLEDGEMENT}

INIFTA is a Research Institute jointly established by the Universidad Nacional de La Plata, the Consejo Nacional de Investigaciones Científicas y Técnicas and the Comisión de Investigaciones Científicas de la Provincia de Buenos Aires.

\section{REFERENCES}

1 A.N. Chemodanov, Ya.M. Kolotyrkin, M.A. Dembrovskin and T.V. Kudryavma. Dokl. Akad. Nauk SSSR. 171 (1966) 1384.

2 A.N. Chemodanov, Ya.M. Kolotyrkin and M.A. Dembrovski1, Elektrokhimiya. $6(1970) 460$.

3 D.A.J. Rand and R Woods, J. Electroanal. Chem. 35 (1972) 209.

4 D.C. Johnson, D.T. Napp and S. Bruckenstem, Electrochim. Acta, 15 (1970) 1493

5 T Biegler, J. Electrochem. Soc., 114 (1967) 1261 
6 T. Bregler. J. Electrochem. Soc.. 116 (1969) 1131.

7 R Parsons and W.H.M. Visscher, J Electroanal. Chem., 36 (1972) 329.

8 A.E. Bolzan. M.E. Martıns and A.J. Arvia, J. Electroanal. Chem., 172 (1984) 221.

9 A.E. Bolzan, M.E Martıns and A.J. Arvia, J. Electroanal. Chem., in press.

10 J W. May. Ind. Eng. Chem.. 57 (1965) 19.

11 R.M. Cerviño, W E Triaca and A.J. Arvia. J. Electroanal. Chem., 182 (1985) 51.

12 J C. Canullo. W.E. Triaca and A.J. Arvia, J. Elcctroanal. Chem., 175 (1984) 337.

13 R.M. Cerviño, A.J. Arvia and W. Vielstich, Surf. Scı , 154 (1985) 623.

14 W.E. Triaca, T. Kessler, J.C Canullo and A.J Arvia. J. Electrochem. Soc., in press.

15 G Ayres and A Meyer. Anal. Chem.. 23 (1951) 299.

16 E B Sandell, Colorımetric Determination of Traces of Metals. Interscience-Wiley, New York, 1959.

17 A.C. Chialvo, W E Triaca and A J. Arvia, J. Electroanal. Chem, 146 (1983) 93.

18 L D Burke and M.B.C. Roche, J. Electroanal. Chem., 164 (1984) 315.

19 A.J Bard (Ed.). Encyclopedia of Electrochemistry of the Elements, Vol. 6. Marcel Dekker, New York. 1976. Ch. 4. p. 170.

20 B.E. Conway, H. Angerstein-Kozlowska. F.C. Ho. J. Klinger, B MacDougall and S. Gottesfeld. Faraday Discuss. Chem. Soc., 56 (1973) 210.

21 S. B1mes and A.J. Arvia, J. Electroanal. Chem., 198 (1986) 137.

22 A.J. Bard, R. Parsons and J. Jordan (Eds.), Standard Potentials in Aqueous Solutions, Marcel Dekker. New York, 1985.

23 R. Lorenz and P.E. Spielmann. Z. Elektrochem., 15 (1909) 293.

24 D.F Untereker and S. Bruckenstein. J. Electrochem. Soc., 121 (1974) 360.

25 A.J Bard and I.F. Faulkner, Electrochemical Methods, Wiley, New York, 1980

26 A.R. Despic in B. Conway, J.O’M. Bockrıs, E. Yeager, S.U M. Khan and R.E. White (Eds.), Comprehensive Treatise of Electrochemistry, Vol. 7, Plenum Press. New York, 1983, p. 518.

27 A.C. Chialvo, W E Triaca and A.J. Arvia, An. Asoc Quim Argent.. 73 (1985) 23.

$28 \mathrm{~S}$ Bilmes, M.C. Giordano and A.J Arvia, J Electrochem. Soc., submitted.

29 A.J. Arvia, J C. Canullo, E. Custıdıano. C.L. Perdriel and W.E Triaca. Electrochım. Acta, in press. 